\title{
Performance Over Time and Durability Assessment of External Thermal Insulation Systems with Artificial Stone Cladding
}

\author{
Sonia Lupica Spagnolo and Bruno Daniotti
}

\begin{abstract}
The contribution describes an experimental programme on durability assessment using the accelerated ageing of an outer wall component consisting of plasterboard support, an external thermal insulation composite system (ETICS) in polystyrene and a cladding that was realised half with natural stone and the other half with cast stone. The sample was placed in front of the climatic chamber by means of a special frame, in the so-called door configuration. During the accelerated ageing, this sample was simultaneously monitored over time using temperatures probes and flowmeter tests in order to evaluate the decay of the thermal performance over time. The experimental research was conducted with the aim of assessing the decay in thermal performance of an ETICS covered with artificial stone, comparing it with a similar stratigraphy but with a natural stone cladding.
\end{abstract}

Keywords Artificial stone $\cdot$ ETICS $\cdot$ Service life $\cdot$ Durability $\cdot$ Accelerated ageing

\section{Introduction}

European economies depend on natural resources, but if current patterns of resource use are maintained in Europe, environmental degradation and depletion of natural resources will continue. The issue has also a global dimension (European Commission 2005). That is why, artificial stones adoption can contribute in reducing the negative environmental impacts generated by the use of natural resources.

Stones used for cladding are exposed to environmental weathering, which is responsible for alterations in their microstructure (e.g. open porosity, pore size distribution, chemical-mineralogical composition of the phases, etc.), that, in turn, results in a modification of physical and mechanical properties (Franzoni et al. 2013).

The main material which is the subject of accelerated ageing is artificial stone made by means of a suitable Portland cement mix, lightweight aggregates and

S. Lupica Spagnolo $(\varangle) \cdot$ B. Daniotti

Architecture, Built Environment and Construction Engineering-ABC Department,

Politecnico di Milano, Milan, Italy

e-mail: sonia.lupica@polimi.it 
colours based on permanent mineral oxides. Different research activities have been undertaken on artificial stones (Fatiguso et al. 2013; Martínez-Martínez et al. 2013; Morillas et al. 2015; Stefanidou et al. 2015).

The catalogue of this product provides 32 different types of cast stone, inside of which different types of shapes are reproduced using suitable moulds, in order to replicate the same aesthetic effect given by the natural stone in the most realistic manner possible.

Depending on the desired effect, the artificial stone can be laid with or without joints and the product for grouting (a two-component lightened mortar) is available in five different colours and in two granulometries (fine-grained, 0/3 mm, or coarsegrained, 3/8 mm) (Table 1).

This artificial stone was used as a finishing layer for the thermal insulation system that was created using EPS 8-cm-thick panels, glued onto a plasterboard support by means of specific fibrate cement-based adhesive, also used as a filler on two layers to allow for the positioning of the $160 \mathrm{~g} / \mathrm{m}^{2}$ glass fibre alkali-resistant mesh; to allow comparison with the natural stone use, the same stratigraphy was realised with a natural stone coating, and the sample placed at the door of a climatic chamber was divided into two portions: one was coated with artificial stone and the other one with natural stone.

Table 1 Technical specifications of the artificial stone cladding

\begin{tabular}{l|l}
\hline Feature & Value \\
\hline Density (in accordance with ASTM C567-14) & $1200 \mathrm{~kg} / \mathrm{m}^{3}$ \\
\hline $\begin{array}{l}\text { Surface mass (depending on the texture and the presence or } \\
\text { absence of the joint in the installation) }\end{array}$ & From 35 to $50 \mathrm{~kg} / \mathrm{m}^{2}$ \\
\hline Medium thickness & $5 \mathrm{~cm}$ \\
\hline Fire-resistance type & M0 \\
\hline Colour stabilising time & $2 / 6$ months \\
\hline Moisture absorption (according to UBC 15-5) & Between 12 and 22\% \\
\hline Absorption during immersion (according to EN 14617-1:2013) & \\
\hline- After 1 h & $7.6 \%$ \\
\hline- After 8 h & $12.5 \%$ \\
\hline- After 24 h & $14.4 \%$ \\
\hline Water vapour permeability (average stone $\mu$ ) & 26.4 \\
\hline Thermal resistance (according to ASTM C177-13) & $0.16 \mathrm{~K} \mathrm{~m} / \mathrm{W}$ \\
\hline Thermal conductivity (according to UNI EN 12667:2002) & $0.1866 \mathrm{~W} / \mathrm{mK}$ (indicative) \\
\hline Compressive strength (according to EN 14617-15:2005) & $21.6 \mathrm{MPa}$ \\
\hline Flexural strength (according to EN 14617-2:2016) & $3.7 \mathrm{MPa}$ \\
\hline $\begin{array}{l}\text { Flexural strength after freezing-thawing (according to EN } \\
\text { 14617-5:2012) }\end{array}$ & $3.2 \mathrm{MPa}$ \\
\hline
\end{tabular}




\section{Experimental Layout Definition}

The evaluation of the decay in thermal performance was conducted by means of relative comparison of the temperatures profiles and flowmeter measurements performed at time zero and after two accelerated ageing cycles. The test sample was placed at the "door configuration" of the climatic chamber: thanks to this configuration, it was possible to simulate the actual behaviour of the sample as the enclosure element between an internal environment (that of the same laboratory) and an external environment (the one imposed inside the climatic chamber). With this in mind, it was decided to perform a sampling that would be appropriately placed in front of the compartment of the climatic chamber, constituting the closing element (hence the "door configuration" designation).

To achieve so, according to the stratigraphy for monitoring the test sample, the size of the sample together with the correct positioning of the temperature sensors and the flowmeter was organised; in the sample, some probes were also positioned in the internal layers in order to verify the thermo-hygrometric profiles of the entire stratigraphy.

The accelerated ageing was programmed in such a way to be able to monitor the thermal properties of two tested coating types over time:

- natural stone ("NAT" type);

- artificial stone ("ART" type).

The accelerated ageing cycle is structured, as shown in Table 2, in two sub-cycles: winter and summer. This cycle was designed based on years of research on thermal insulation systems in the climate context of northern Italy, considering the average frequency of critical events of winter freezing-thawing and summer heat shock on a statistical basis (Daniotti et al. 2008).

Table 2 Specifications of the adopted accelerated ageing cycle

\begin{tabular}{|c|c|c|c|c|c|c|c|}
\hline $\begin{array}{l}\text { Sub- } \\
\text { cycle }\end{array}$ & Phase & $\begin{array}{l}\text { Air tem- } \\
\text { perature } \\
\left({ }^{\circ} \mathrm{C}\right)\end{array}$ & $\mathrm{RH}(\%)$ & $\begin{array}{l}\text { Phase } \\
\text { duration } \\
\text { (min) }\end{array}$ & $\begin{array}{l}\text { Included } \\
\text { transi- } \\
\text { tory } \\
\text { duration } \\
\text { (h) }\end{array}$ & Repetition & $\begin{array}{l}\text { Total } \\
\text { duration } \\
\text { (h) }\end{array}$ \\
\hline \multirow[t]{3}{*}{ Winter } & Rain & $5 \pm 1$ & 100 & 60 & \multirow[t]{3}{*}{6} & \multirow[t]{3}{*}{10} & \multirow[t]{3}{*}{60} \\
\hline & Freeze & $-20 \pm 1$ & - & 90 & & & \\
\hline & $\begin{array}{l}\text { Winter } \\
\text { heat }\end{array}$ & $30 \pm 1$ & $50 \pm 1$ & 60 & & & \\
\hline \multirow{2}{*}{$\begin{array}{l}\text { Summer } \\
\text { (thermal } \\
\text { shock) }\end{array}$} & Dry heat & $80 \pm 1$ & $15 \pm 1$ & 60 & \multirow[t]{2}{*}{3} & \multirow[t]{2}{*}{25} & \multirow[t]{2}{*}{75} \\
\hline & Rain & $20 \pm 1$ & 100 & 60 & & & \\
\hline
\end{tabular}




\subsection{Description of the "Winter" Sub-cycle}

1. Rain phase (60 $\mathrm{min})$ : the test samples were sprayed with water to simulate a rainy event. The air inside the climatic chamber was kept at a constant temperature of $5^{\circ} \mathrm{C}$.

2. Freeze phase (duration $90 \mathrm{~min}$ ): the air temperature inside the compartment containing the wet test samples was cooled to $-20{ }^{\circ} \mathrm{C}$ and subsequently kept constant at that value.

3. "Hot winter" phase (duration $60 \mathrm{~min}$ ): the temperature and the air humidity are kept constant, respectively, at $30{ }^{\circ} \mathrm{C}$ and $50 \%$ for a duration of $60 \mathrm{~min}$.

\subsection{Description of the "Summer" Sub-cycle}

1. Dry heat (duration $60 \mathrm{~min}$ ): the temperature and humidity were kept constant, respectively, at $80{ }^{\circ} \mathrm{C}$ and at $15 \%$ for a duration of $60 \mathrm{~min}$.

2. Rain phase $(60 \mathrm{~min})$ : the test samples were evenly sprayed with water to simulate a rainy event. The air inside the climatic chamber was kept at a constant temperature of $20^{\circ} \mathrm{C}$.

The accelerated ageing cycle consisted of ten repetitions of the winter sub-cycle, followed by 25 repetitions of the summer sub-cycle. This ageing cycle was repeated twice.

The expected time steps were therefore as follows:

$t_{0}=$ after drying of the sample, before the accelerated ageing;

$t_{1}=$ after one accelerated ageing cycle;

$t_{2}=$ after two accelerated ageing cycles.

\section{Characterisation Tests and Analysis of the Degradation Over Time}

For the "door configuration" sample, 3-time monitoring steps were carried out with the following characterisation tests and degradation analysis:

- photographic survey;

- measuring thermal resistance according to ISO 9869-1:2014;

- continuous measurement of heat flow in the flowing section;

- continuous measurements of temperature for analysis of the temperature profiles in the cross section (by placing four surface probes and four interstitial probes on the sample combined with environmental temperature probes). 
As above stated, the stratigraphy for this sample is common to both portions until the second coating of the insulating layer. This "pre-coating" stratigraphy is as follows:

- plasterboard support with $15 \mathrm{~mm}$ thickness;

- 8-cm EPS panels, glued onto the substrate by means of plasterboard with specific fibrate cement-based glue for application of the adhesive (or smoothing) for coating systems;

- first EPS panel coating layer always with fibrate glue;

- $160 \mathrm{~g} / \mathrm{m}^{2}$ alkali-resistant fibreglass mesh;

- second coating layer always with fibrate adhesive, similar to the one used as an adhesive and for the first coating layer.

The two portions of the sample, differentiated by the type of coating from this point onwards, have the following additional layers:

for the PART COVERED WITH ARTIFICIAL STONE (for brevity called “ART”)

- first coating with cement-based glue and natural hydraulic lime;

- glass fibre mesh with anti-alkaline primer weighing $315 \mathrm{~g} / \mathrm{m}^{2}$;

- second coating always with cement-based glue and natural hydraulic lime;

- cast stone, jointed (for the drying of any potential glue) with a two-component lightened mortar.

for the PART COVERED WITH NATURAL STONE (for brevity called "NAT")

- one-component Portland cement-based adhesive and synthetic resins with high elasticity;

- natural stone, jointed (for drying any potential glue) with traditional mortar.

\section{Preparation of the Experimental Set-Up}

The previously described cycle specifications were translated into operating plans for programming of the climate chamber in compliance with the necessary precedence.

In the testing phase of the set cycles in the operational plans, the actual duration of the same cycle was measured, including transients, lasted about $135 \mathrm{~h}$.

After having programmed the climatic chamber, tested the individual phases of the cycle and measured the necessary transitional times, it was possible to prepare a realistic experimental plan that also takes into account the appropriate manual operations involved between one ageing cycle and another.

To allow placing the test sample in front of the climatic chamber, an ad hoc structure made and fixed above the carriage of the door of the climatic chamber was realised and installed. This steel structure allows the placement of a sample with a maximum size of $106 \times 106 \mathrm{~cm}$. 
Fig. 1 Temperature probe positioning

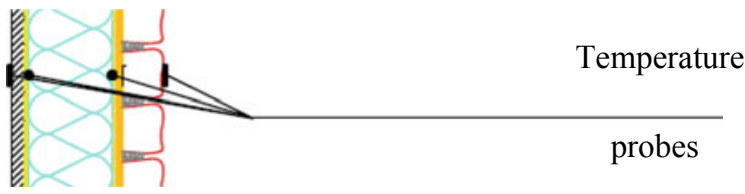

The specimen was made in accordance with the stratigraphy and the dimensions above indicated. Between the two coating sections, an acetic silicone separation joint was applied. This material was also used for fixing the plasterboard to the containment frame.

The probes to measure the temperature were placed on the following interfaces:

- Pos 1-exposed surface of the plasterboard (lab side);

- Pos 2-interstitial plasterboard surface, before laying the glue of the EPS;

- Pos 3-pre-bonding coating surface, which corresponds:

- for the "NAT" part, to the surface after the second coating of the EPS;

- for the "ART" part, to the surface after the second coating;

- Pos 4-exposed surface of the cladding (climatic chamber side), in correspondence with the surface's centre of gravity on the coating ashlar (Fig. 1).

These temperature probes were placed and then fixed by means of mastic along the electrical cable, in order to prevent the probe from moving when performing the sample or the experimental test. The cables were then positioned vertically along with the sample and passed through the slots and the plastic pipes arranged in the lower part of the sample itself.

During the construction of the sample, it was taken into account that the two surface coating side probes needed to be placed in the centre of gravity of the surface of an ashlar. Therefore, as the other temperature probes (surface probe plasterboard side and probes to lose in the flowing section) must be aligned with these through the flowing section, the precise position of the superficial probes applied on the coating was preliminarily determined even before sampling began.

Prior to the positioning of the sample in front of the climatic chamber, a visual inspection of the surface and a photographic survey at time zero were carried out.

\subsection{Specimen Positioning in Front of the Climatic Chamber}

The test sample packaged was carried inside the laboratory and fixed inside the appropriate steel frame, which was previously anchored onto the closing carriage of the climatic chamber (Fig. 2).

In order to ease transportation and monitoring activities, a cart was placed in front of the climatic chamber, and the sample was realised within this steel frame.

After placing the sample in front the climatic chamber, both of the flowmeter probes and the surface temperature probes (internal and external) were fixed down, 

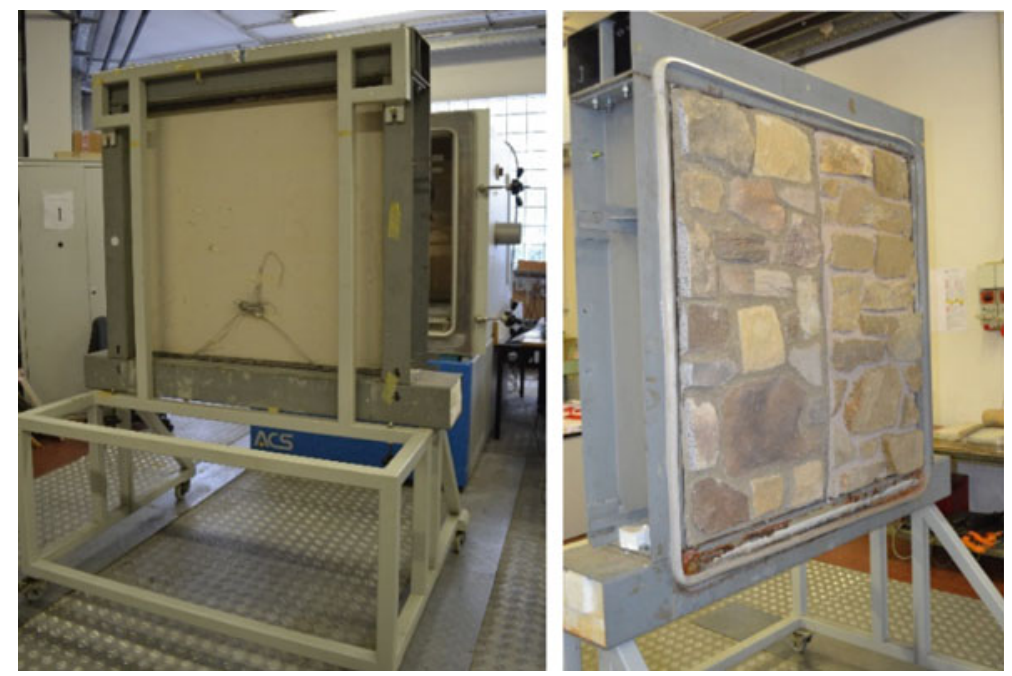

Fig. 2 Views of "door" sample in front of the climatic chamber before the sensor wiring

and the connection of these to the datalogger was made to allow for the continuous acquisition of data.

For this sample, the continuous measurement of temperatures and heat flows along the cross section was performed, keeping the stationary conditions of $5{ }^{\circ} \mathrm{C}$ and $50 \%$ RH inside the climatic chamber (Fig. 3).

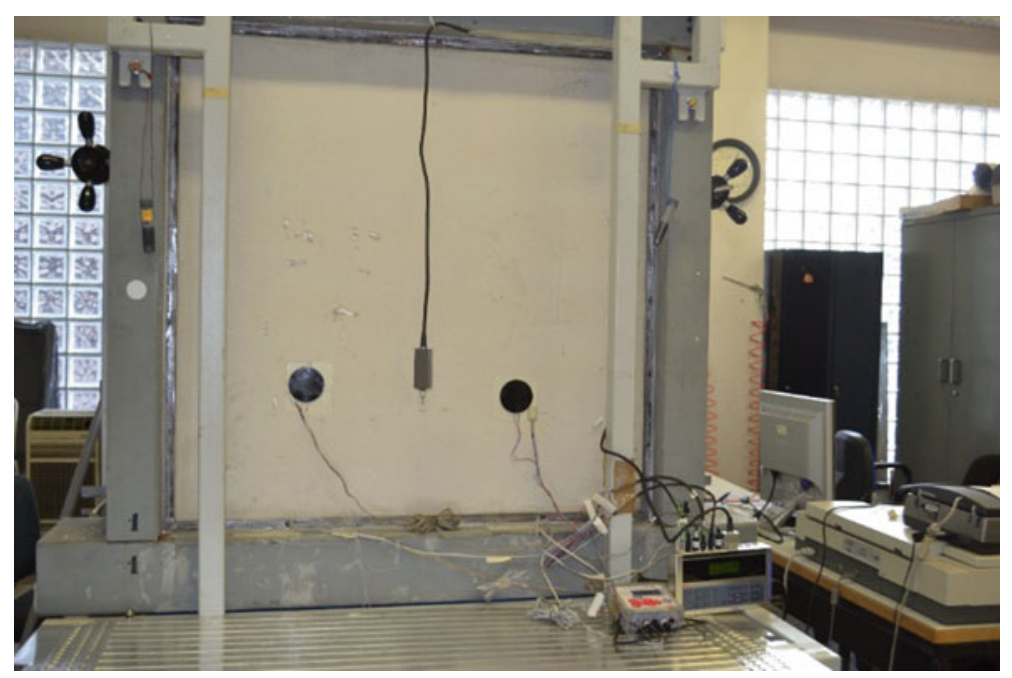

Fig. 3 Sample view in front of the climatic chamber and sensor wiring 


\subsection{Exposure of Test Samples to Accelerated Ageing Cycles}

After having carried out the characterisation survey at time zero, the sample was exposed to the designed accelerated ageing cycles: as envisaged in the preliminary stage and in the preparation of the experimental set-up, the sample was subjected to two cycles of accelerated ageing in a climatic chamber, each consisting of ten repetitions of the winter sub-cycle (rain followed by a freezing phase at $-20{ }^{\circ} \mathrm{C}$, then by a warm winter phase at $30{ }^{\circ} \mathrm{C}$ ) and 25 repetitions of the thermal shock summer sub-cycle (dry heat at $80{ }^{\circ} \mathrm{C}$ followed by rain).

At each time step, the climatic chamber was opened, the photographic survey was carried out on the surface of the test sample and the colorimetric measurement was taken in order to verify any variations in colour. Moreover, the flowmeter trend was constantly monitored, as well as the profile of the flowing section temperatures during the accelerated ageing.

\section{Results}

The surface temperature on the cast stone showed smaller variations in absolute values than the natural stone, demonstrating the fact that the thermal conductivity of the artificial stone was less than the natural stone one. This means that when the outside temperature drops, the surface temperature of the cast stone decreases less than the natural stone, and conversely, when the outside temperature rises, the surface of the artificial stone is not as hot as the natural stone.

This evidence is attributable to the fact that the thermal conductivity of the cast stone is smaller than the natural stone; this is a characteristic that causes the surface temperature variations to be smaller in the artificial stone compared to the ones that are found in the natural stone. This is regardless of the fact that the adhesive mortar used for the joints of the cast section itself has thermal properties better than the in the mortar used for natural stone.

Through flowmeter measures, moreover, it was possible to determine the trend of the thermal resistance over time, comparing the initial values detected on two of the sample sections at the door with the measured values as a result of the two steps of accelerated ageing in the laboratory.

For the measurement of thermal resistance, the method of progressive averages described in ISO 9869-1:2014 was used. Considered as 100 the initial value detected at time zero for both types of coating at the door of the sample, the following trend of the performance decay over time is showed in the following figure.

From the following graph, it is clear that after a decay in thermal resistance of the same amount of both the sample portions (mainly due to the increase of moisture content associated with exposure to rain), at time " $t_{2}$ ", both parts demonstrated mitigation of the initial performance decay. Of the two, the section coated with cast stone showed better thermal behaviour as a result of the accelerated ageing (Fig. 4). 
Fig. 4 Trend percentage of thermal resistances in the sample at the door (the curve relating to the coated section with artificial stone is in yellow and the one in brown is with natural stone)

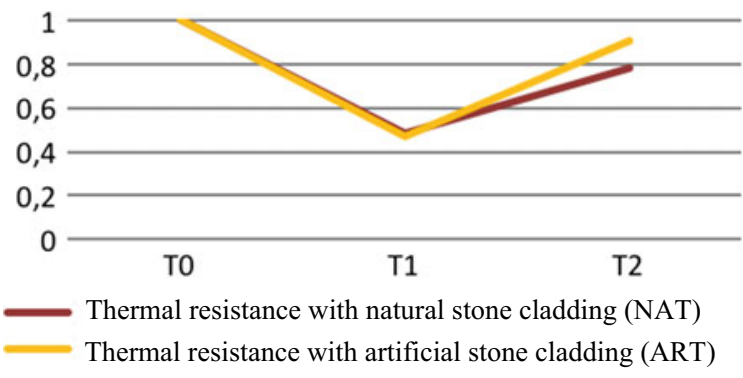

Specifically, with respect to the thermal resistance value before the accelerated ageing:

$-t_{1}$ in both solutions show a halving of the thermal resistance;

- at $t_{2}$, the thermal resistance of the section of the natural stone showed a decrease of approximately $22 \%$, while that of the artificial stone section decreased by approximately $9 \%$ (and therefore a performance decay of around $13 \%$ less than natural stone).

\section{Concluding Remarks}

Following the described accelerated ageing, the experimentation above described showed that:

- considering only the physical degradation, both the natural stone cladding and the artificial stone cladding did not reveal cracks in the stone, delamination or any mechanical type effects;

- the cast stone cladding performed, at time zero and as a result of accelerated ageing cycles, a better thermal behaviour than the natural stone; specifically, the artificial stone cladding shows a lower thermal conductivity, and after two accelerated ageing cycles, a decay in thermal resistance by approximately $13 \%$ less than the of natural stone;

- the presence of the stone coating generally involved a thermal shock mitigation effect;

- it is advisable to carry out colorimetric measurements on single-stone blocks in order to precisely evaluate the colorimetric variations of the coated surfaces; eventually, considering how the moisture content has an impact on the component's thermal behaviour and taking into account the porosity of the coating materials, it is also advisable to assess the progress of thermo-hygrometric behaviour over time through simulations with the appropriate "Heat and Moisture Transfer" calculation software. 
Acknowledgements The research programme was carried out in collaboration with Geopietra S.r.1.

\section{References}

Daniotti, B., Lupica Spagnolo, S., \& Paolini, R. (2008). Climatic data analysis to define accelerated ageing for reference service life evaluation. In 11DBMC International Conference on Durability of Building Materials and Components, (May).

European Commission. (2005). COM (2005) 670 Thematic Strategy on the sustainable use for natural resources.

Fatiguso, F., et al. (2013). Investigation and conservation of artificial stone facades of the early XX century: A case study. Construction and Building Materials, 41, 26-36.

Franzoni, E., et al. (2013). Artificial weathering of stone by heating. Journal of Cultural Heritage, 14(3 SUPPL), 85-93. Elsevier Masson SAS.

Martínez-Martínez, J., et al. (2013). Non-linear decay of building stones during freeze-thaw weathering processes. Construction and Building Materials, 38, 443-454.

Morillas, H., et al. (2015). Nature and origin of white efflorescence on bricks, artificial stones, and joint mortars of modern houses evaluated by portable Raman spectroscopy and laboratory analyses. Spectrochimica Acta-Part A: Molecular and Biomolecular Spectroscopy, 136(PB), $1195-1203$.

Stefanidou, M., Pachta, V., \& Papayianni, I. (2015). Design and testing of artificial stone for the restoration of stone elements in monuments and historic buildings. Construction and Building Materials, 93, 957-965. Elsevier Ltd.

\section{Standards}

ISO 9869-1:2014 Thermal insulation-Building elements-In-situ measurement of thermal resistance and thermal transmittance heat flowmeter method.

ASTM C567-14 Standard Test Method for Determining Density of Structural Lightweight Concrete ASTM C177-13 Standard Test Method for Steady-State Heat Flux Measurements and Thermal Transmission Properties by Means of the Guarded-Hot-Plate Apparatus

EN 14617-1:2013 Agglomerated stone-Test methods-Part 1: Determination of apparent density and water absorption

EN 14617-2:2016 Agglomerated stone-Test methods—Part 2: Determination of flexural strength (bending)

EN 14617-5:2012 Agglomerated stone-Test methods-Part 5: Determination of freeze and thaw resistance

EN 14617-15:2005 Agglomerated stone-Test methods-Part 15: Determination of compressive strength

UNI EN 12667:2002 Prestazione termica dei materiali e dei prodotti per edilizia—Determinazione della resistenza termica con il metodo della piastra calda con anello di guardia e con il metodo del termoflussimetro-Prodotti con alta e media resistenza termica [Thermal performance of building materials and products - Determination of thermal resistance by means of guarded hot plate and heat flow meter methods—Products of high and medium thermal resistance] 
Open Access This chapter is licensed under the terms of the Creative Commons Attribution 4.0 International License (http://creativecommons.org/licenses/by/4.0/), which permits use, sharing, adaptation, distribution and reproduction in any medium or format, as long as you give appropriate credit to the original author(s) and the source, provide a link to the Creative Commons license and indicate if changes were made.

The images or other third party material in this chapter are included in the chapter's Creative Commons license, unless indicated otherwise in a credit line to the material. If material is not included in the chapter's Creative Commons license and your intended use is not permitted by statutory regulation or exceeds the permitted use, you will need to obtain permission directly from the copyright holder.



